CASE REPORT

\title{
Growth pattern and body proportion in a female with short stature homeobox-containing gene overdosage and gonadal estrogen deficiency
}

\author{
Tsutomu Ogata, Mikako Inokuchi and Masamichi Ogawa ${ }^{1}$ \\ Department of Pediatrics, Keio University School of Medicine, Tokyo and ${ }^{1}$ Ogawa Endocrine Clinic, Nagoya, Japan
}

(Correspondence should be addressed to T Ogata, Department of Pediatrics, Keio University School of Medicine, 35 Shinanomachi, Shinjuku-ku, Tokyo 160-8582, Japan; Email: t-ogata@po.iijnet.or.jp)

\begin{abstract}
Objective: To report on growth pattern and body proportion in the combination of short stature homeobox-containing gene (SHOX) overdosage and gonadal estrogen deficiency. Design: Auxological studies in a 20-year-old Japanese female with 45,X[28]/46,X,psu idic(X)(q28)[72], gonadal estrogen deficiency, and SHOX duplication on the idic $(\mathrm{X})$ chromosome, who received sex steroid replacement therapy from 16 years 8 months of age.

Methods: Growth pattern and body proportion were assessed by the age-matched standards for Japanese females.

Results: She continued to grow with a mean height velocity of $5.0 \mathrm{~cm} /$ year between 8 and 12 years of age and $4.4 \mathrm{~cm} /$ year between 12 and 16 years 8 months of age, and ceased to grow shortly after the replacement therapy. The standard deviation score (SDS) for height was $-0.9,-1.4,+0.7$ and +0.8 at $8,12,16$ years 8 months and 20 years of age respectively. She showed a unique change in body proportion in her middle teens. At 8, 12, 16 years 8 months and 20 years of age, the SDS for sitting height $(\mathrm{SH})$ was $-0.8,-1.1,-0.9$ and -0.6 respectively, the SDS for leg length (LL) was $-1.2,-1.4,+1.1$ and +1.4 respectively, and the SDS for SH/LL ratio was $+0.6,+0.4$, -1.6 and -1.7 respectively.

Conclusions: The results provide further support for the notion that the combination of SHOX overdosage and gonadal estrogen deficiency permits continued growth with a roughly constant height velocity throughout the pubertal period of normal children, and suggest that the height gain in that period is primarily ascribed to the LL increase, as expected from SHOX expression in the distal limb bones.
\end{abstract}

European Journal of Endocrinology 147 249-254

\section{Introduction}

SHOX (short stature homeobox-containing gene) is the first gene that has been shown to be relevant to the development of specific features in Turner syndrome. Clinical studies in patients with intragenic SHOX mutations and pseudoautosomal microdeletions involving SHOX as the sole disease gene have shown that SHOX haploinsufficiency causes not only short stature but also Turner skeletal features such as high arched palate, short neck, short metacarpals, cubitus valgus and Madelung deformity $(1-4)$. Consistent with the distribution of skeletal lesions, SHOX is exclusively expressed in the first and second pharyngeal arches and in the developing distal limb bones of human embryos (3). Since SHOX haploinsufficiency results in compromised linear growth and unbalanced premature growth plate fusion of the distal limb bones $(2,4,5)$, this implies that SHOX normally functions as a promoter for linear growth and as a repressor for growth plate fusion.

Growth failure and skeletal features in SHOX haploinsufficiency tend to be more severe in females than in males and to become obvious with puberty in individuals with normal gonadal function $(2,4)$. Indeed, Leri-Weill dyschondrosteosis characterized by Madelung deformity and mesomelia is predominantly exhibited by pubertal or adult females. In this context, it has been suggested that gonadal estrogens exert a maturational effect on skeletal tissues that are susceptible to unbalanced premature growth plate fusion because of SHOX haploinsufficiency, facilitating growth deficiency and skeletal lesions in a femaledominant and pubertal tempo-influenced fashion (2). This notion postulates that SHOX haploinsufficiency and gonadal estrogens exert a synergic effect on 
skeletal growth and maturation, and explains, in terms of serum estrogen concentration and the tempo of pubertal development, why skeletal lesions in SHOX haploinsufficiency are usually severe in early maturing females and are apparently absent or remain mild in males $(2,4)$.

Recently, it has been reported that the opposite combination of SHOX overdosage and gonadal estrogen deficiency leads to tall adult height because of continued growth with an almost constant height velocity from childhood through the pubertal period of normal children (6). This has been ascribed to the cooperation between SHOX overdosage and gonadal estrogen deficiency, which should exert a beneficial effect on linear growth and a marked suppressive effect on skeletal maturation. Since the growth pattern is similar to that in estrogen resistance or aromatase deficiency, which lacks biological effects of both gonadal and extragonadal estrogens (7), this suggests that an extra copy of SHOX has a potential to override the growthsuppressing and skeletal-maturing effect of extragonadal estrogens (6). Furthermore, tall stature with long legs has been reported in middle to late teenage females with $\operatorname{der}(\mathrm{X})$ chromosomes accompanied by distal Xp duplication and gonadal dysgenesis, suggesting that tall stature in the combination of SHOX overdosage and gonadal estrogen deficiency may primarily be ascribed to long legs $(8-10)$.

However, clinical studies, especially longitudinal growth studies, remain poor for the combination of proven SHOX overdosage and gonadal estrogen deficiency, so that further studies are necessary to define the clinical features of the unique combination. In this paper, we report on longitudinal growth pattern and body proportion in a female with the association of SHOX overdosage with gonadal estrogen deficiency.

\section{Patient and methods}

\section{Patient}

This Japanese female was born at 40 weeks of gestation after an uncomplicated pregnancy and delivery. At birth, the length was $46.9 \mathrm{~cm}(-1.1$ s.D. $)$ and the weight $2.95 \mathrm{~kg}$ ( -0.4 S.D.). The parents were nonconsanguineous and clinically normal.

At 15 years 5 months of age, she presented with primary amenorrhea. Physical examination revealed no abnormality except for the lack of pubertal development. There were no discernible minor or major anomalies. The height was $154.7 \mathrm{~cm}(-0.3$ s.D.) and the weight $56.9 \mathrm{~kg}$ (+0.6 S.D.). Basal serum folliclestimulating hormone (FSH) was 47.6 IU/l (agematched normal range, 1.4-10.1 IU/l), luteinizing hormone $9.0 \mathrm{IU} / \mathrm{l}(0.2-15.1 \mathrm{IU} / \mathrm{l})$, and estradiol below $30 \mathrm{pmol} / \mathrm{l}(45-620 \mathrm{pmol} / \mathrm{l})$. She received conjugated estrogen (CE) $(0.625 \mathrm{mg} /$ day $)$ from 16 years 8 months of age, and cyclic hormone replacement therapy consisting of $\mathrm{CE}$ on days 1-14, CE plus medroxyprogesterone acetate ( $5 \mathrm{mg}$ /day) on days $15-$ 21, and no drug on days 22-28 from 17 years 11 months of age. At present, she is 20 years old and shows sufficient pubertal development and regular menses.

\section{Methods}

Conventional and molecular cytogenetic studies After obtaining informed consent, chromosome analysis was performed on peripheral lymphocytes by G-banding. Fluorescence in situ hybridization (FISH) analysis was performed for lymphocyte metaphase spreads, using probes for SHOX (2), DXZ1 (centromere) (Vysis, http://www.vysis.com/), the Xq telomere region (Vysis), and the whole X chromosome painting (WCPX) (Vysis). The SHOX probe was labeled with digoxigenin and detected by rhodamine anti-digoxigenin, and the remaining probes were detected according to the manufacturer's protocol.

Auxological studies Statural growth was evaluated by the longitudinal height and height velocity standards for Japanese females (11). Target height (TH) and target range (TR) were obtained from the equations of Ogata et al. (12) (a modified Tanner's equation for the Japanese with a positive height secular trend). Sitting height (SH), leg length (LL, height minus $\mathrm{SH}$ ), and SH/LL ratio were assessed by the age-matched standards for Japanese females (13). Pubertal stage was assessed by the classification of Tanner (14). Bone age was determined by the TW-2 method standardized for the Japanese (15).

\section{Results}

\section{Conventional and molecular cytogenetic studies}

Chromosome analysis showed a 45,X[28]/46,X,psu $\operatorname{idic}(X)(q 28)[72]$ karyotype. FISH analysis revealed duplication of SHOX and DXZ1 on the idic(X) chromosome and deletion of the Xq telomere region from the $\operatorname{idic}(\mathrm{X})$ chromosome (Fig. 1). The WCPX probe homogeneously stained the entire $\operatorname{idic}(\mathrm{X})$ chromosome as well as the normal $\mathrm{X}$ chromosome.

\section{Auxological studies}

The data are summarized in Table 1 and Fig. 2. She had normal to low-normal height until her early teens, but continued to grow with a roughly constant height velocity until the initiation of $\mathrm{CE}$ replacement therapy. The mean height velocity was $5.0 \mathrm{~cm} /$ year between 8 and 12 years of age, and $4.4 \mathrm{~cm} /$ year between 12 and 16 years 8 months of age. She ceased to grow shortly after the CE replacement therapy with pubertal 


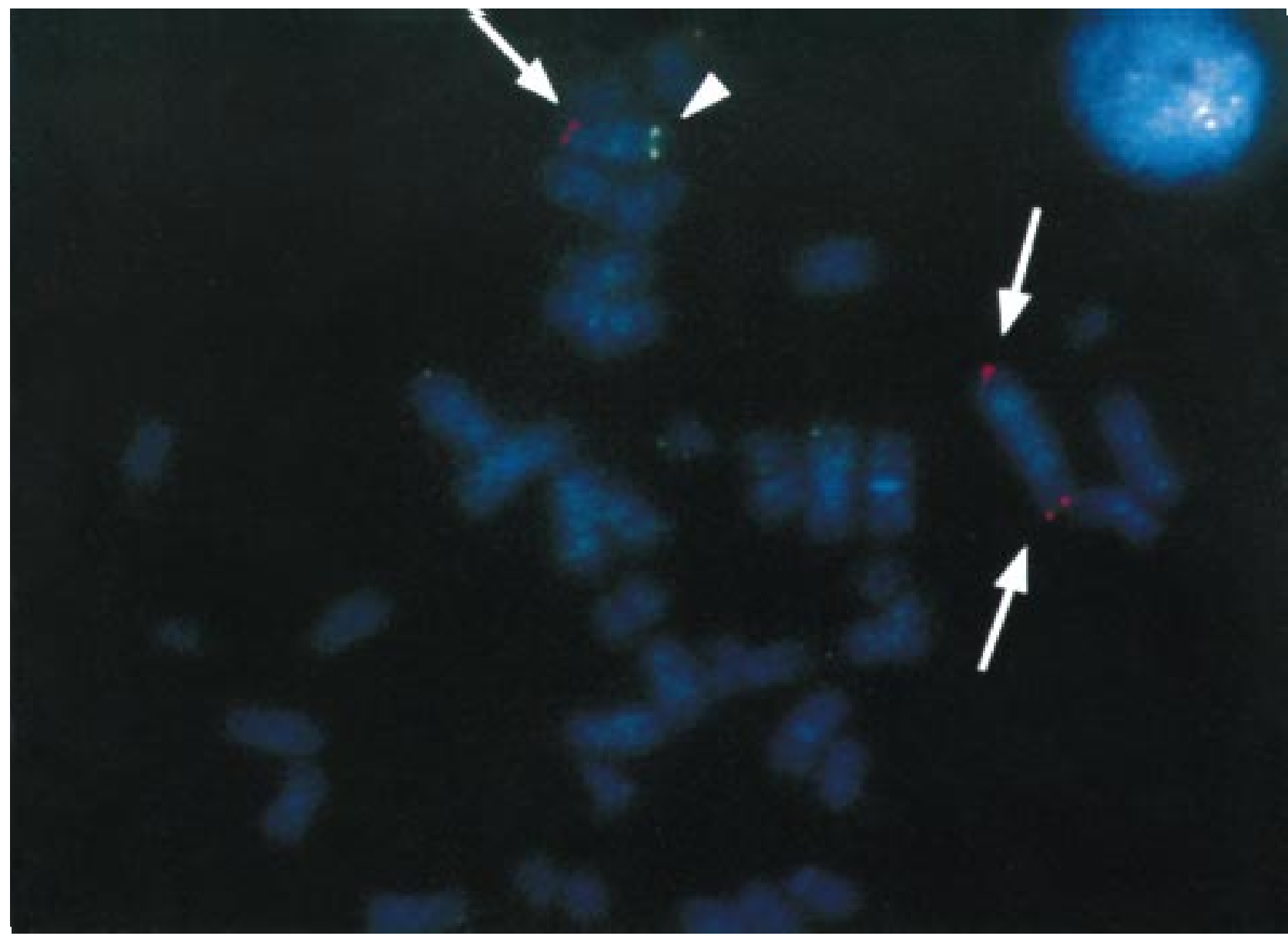

Figure 1 FISH analysis for a 46,X,idic(X)(q28) lymphocyte. SHOX is detected on both ends of the idic(X) chromosome and one end of the normal $X$ chromosome (arrows), whereas the $X q$ telomere region is identified on the normal $X$ chromosome alone (arrowhead).

and bone age progression, and had a final height of $161.9 \mathrm{~cm} \quad(+0.8$ S.D.), which was above her TH $(159 \mathrm{~cm},-0.3$ S.D.) and within her TR (151$167 \mathrm{~cm},-1.3 \pm 1.9$ S.D.). The standard deviation score (SDS) for height gradually decreased from -0.9 at 8 years of age to -1.4 at 12 years of age and, then, steadily increased to +0.7 at 16 years 8 months of age and finally to +0.8 at 20 years of age.
She showed a dramatic change in body proportion in her middle teens. The SDS for SH remained almost constant from 8 until 20 years of age with the values of $-0.8,-1.1,-0.9$ and -0.6 at $8,12,16$ years 8 months and 20 years of age respectively. By contrast, the SDS for LL, although it remained almost constant from 8 until 12 years of age with the values of -1.2 at 8 years of age and -1.4 at 12 years of age, steadily

Table 1 Height, sitting height (SH), leg length (LL) and SH/LL ratio of this female.

\begin{tabular}{|c|c|c|c|c|c|c|c|c|c|c|c|c|}
\hline & \multicolumn{12}{|c|}{ Age (years:months) } \\
\hline & $0: 0$ & $1: 7$ & $8: 0$ & 9:0 & $10: 0$ & $11: 0$ & $12: 0$ & $13: 10$ & $15: 5$ & $16: 8$ & 18:0 & $20: 0$ \\
\hline $\begin{array}{l}\text { Height }(\mathrm{cm}) \\
\text { (SDS) }\end{array}$ & $\begin{array}{c}46.9 \\
(-1.1)\end{array}$ & $\begin{array}{c}77.0 \\
(-1.2)\end{array}$ & $\begin{array}{c}119.9 \\
(-0.9)\end{array}$ & $\begin{array}{l}125.7 \\
(-0.8)\end{array}$ & $\begin{array}{l}130.0 \\
(-0.9)\end{array}$ & $\begin{array}{c}135.5 \\
(-1.1)\end{array}$ & $\begin{array}{c}139.9 \\
(-1.4)\end{array}$ & $\begin{array}{l}150.3 \\
(-1.0)\end{array}$ & $\begin{array}{c}154.7 \\
(-0.3)\end{array}$ & $\begin{array}{l}160.3 \\
(+0.7)\end{array}$ & $\begin{array}{l}161.6 \\
(+0.8)\end{array}$ & $\begin{array}{l}161.9 \\
(+0.8)\end{array}$ \\
\hline $\mathrm{SH}(\mathrm{cm})$ & - & - & 66.7 & 68.7 & 71.3 & 73.5 & 76.0 & 81.3 & 82.0 & 83.0 & $\begin{array}{c}(+0.0) \\
84.3\end{array}$ & $\begin{array}{c}(+0.0) \\
84.3\end{array}$ \\
\hline (SDS) & - & - & $(-0.8)$ & $(-0.8)$ & $(-0.6)$ & $(-0.6)$ & $(-1.0)$ & $(-1.0)$ & $(-0.9)$ & $(-0.9)$ & $(-0.6)$ & $(-0.6)$ \\
\hline LL (cm) & - & - & 53.2 & 57.0 & 58.7 & 62.0 & 63.9 & 69.0 & 72.7 & 77.0 & 77.3 & 77.5 \\
\hline (SDS) & - & - & $(-1.2)$ & $(-1.1)$ & $(-1.5)$ & $(-1.1)$ & $(-1.4)$ & $(-0.8)$ & $(+0.1)$ & $(+1.1)$ & $(+1.4)$ & $(+1.4)$ \\
\hline $\mathrm{SH} / \mathrm{LL}$ ratio & - & - & 1.25 & 1.21 & 1.21 & 1.19 & 1.19 & 1.18 & 1.13 & 1.08 & 1.09 & 1.09 \\
\hline (SDS) & - & - & $(+0.6)$ & $(+0.3)$ & $(+0.9)$ & $(+0.8)$ & $(+0.4)$ & $(+0.2)$ & $(-0.9)$ & $(-1.6)$ & $(-1.7)$ & $(-1.7)$ \\
\hline
\end{tabular}



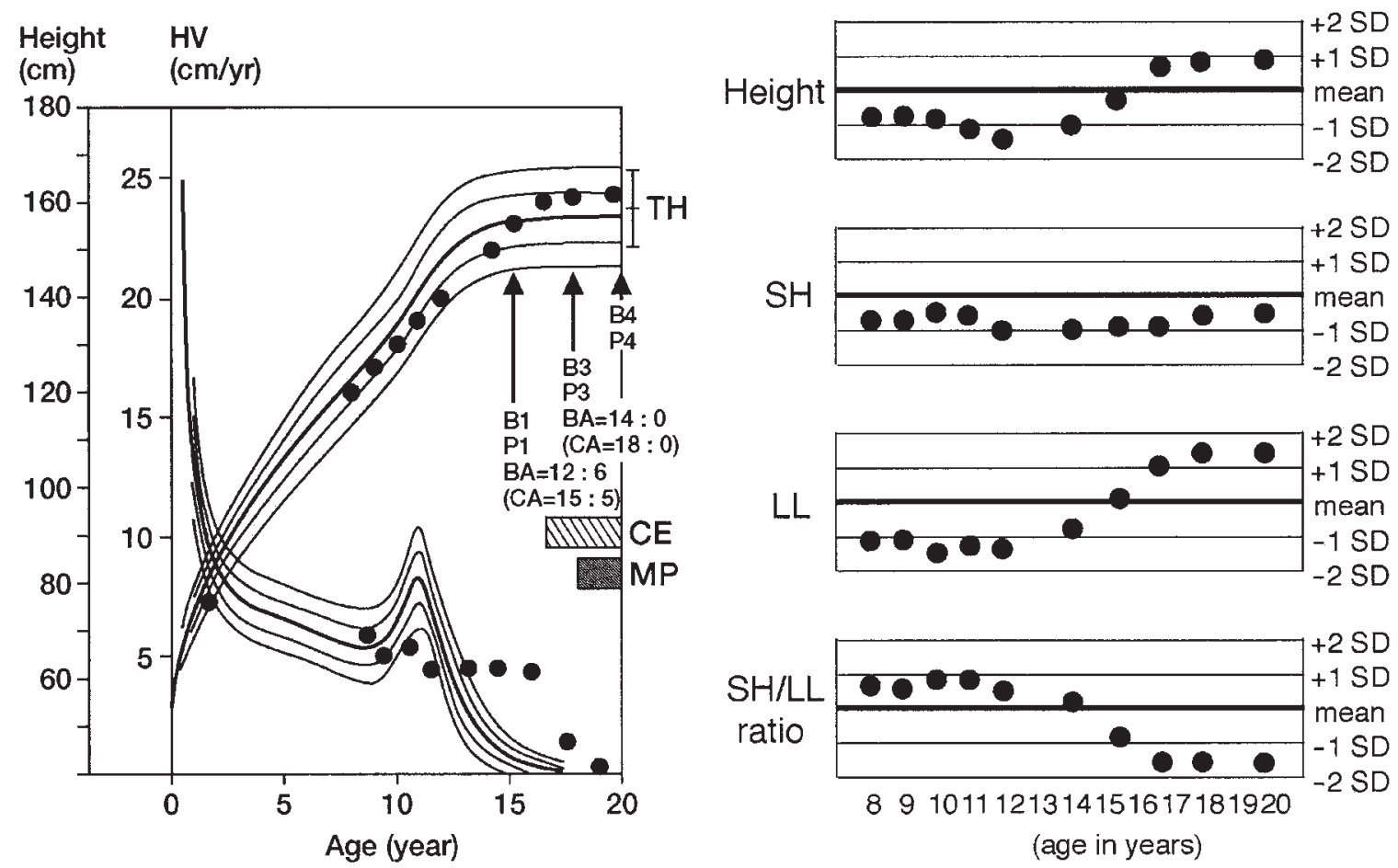

Figure 2 Left. Growth chart: actual heights and height velocities are plotted on the longitudinal height and height velocity (HV) standards for Japanese females (the mean \pm 1 S.D., and \pm 2 S.D.). Target height $(T H)$ is shown, together with target range indicated by the vertical bar. Tanner pubertal stage (B: breast; $P$ : pubic hair) and bone age (BA) are indicated, together with the chronological age $(C A)$ at the time of examination. Conjugated estrogen (CE) $(0.625 \mathrm{mg} /$ day) has been started from 16 years 8 months of age, followed by cyclic hormone replacement therapy consisting of CE and medroxyprogesterone acetate (MP) (5 mg/day) from 17 years 11 months of age. Right. Age change in the SDS for height, sitting height (SH), leg length (LL, height minus SH), and SH/LL ratio.

increased thereafter to +1.1 at 16 years 8 months of age and finally to +1.4 at 20 years of age. Consequently, the SDS for SH/LL ratio remained almost constant from 8 until 12 years of age with the values of +0.6 at 8 years of age and +0.4 at 12 years of age and, then, steadily decreased to -1.6 at 16 years 8 months of age and finally to -1.7 at 20 years of age.

\section{Discussion}

This female had a large isodicentric X chromosome with the breakpoint at Xq28. Consistent with the X chromosome rearrangement, endocrine studies showed FSH-dominant hypergonadotropic hypogonadism, which has been reported in Turner syndrome with gonadal dysgenesis (16), and FISH analysis revealed SHOX duplication on the idic(X) chromosome. Thus, this female represents a further case with the combination of SHOX overdosage and gonadal estrogen deficiency.

She exhibited a characteristic growth pattern. She continued to grow with a roughly constant height velocity from childhood through the middle teens in association with the upward shift of the height SDS until the initiation of CE. The growth pattern in her middle teens is noteworthy, because it is similar to that of the previously reported 29-year-old Japanese female with tall stature $(172 \mathrm{~cm},+2.9$ S.D. $)$ and $45, X[40] / 46, X, \operatorname{der}(X)[60]$ accompanied by SHOX duplication on the $\operatorname{der}(\mathrm{X})$ chromosome and gonadal dysgenesis untreated until 19 years of age (6). In this regard, it has been suggested that the growth pattern and tall stature of the previously reported female are inexplicable by SHOX duplication or gonadal estrogen deficiency alone but is explainable by assuming a synergic effect of the two factors (6). Thus, the growth pattern of this female would also be accounted for by the synergic effect of SHOX overdosage and gonadal estrogen deficiency.

The body proportion showed a unique change with age. The SDS for SH remained almost constant, but the SDS for LL steadily increased and the SDS for the SH/LL ratio steadily decreased in the middle teens. This implies that the height gain in her middle teens is primarily ascribed to the LL increase. Since SHOX is expressed in the distal limb region (3), and pure gonadal dysgenesis is usually associated with eunuchoid habitus with relatively long limbs $(17,18)$, it is inferred that SHOX overdosage and gonadal estrogen deficiency have primarily exerted a synergic effect on the limb bones, leading to the marked increase in the LL and 
resultant change in the body proportion. This idea would explain why relatively tall stature in Klinefelter patients is almost totally ascribed to increased LL (19, 20), because Klinefelter patients have three copies of SHOX and hypogonadism.

For the growth pattern and body proportion of this female, the mosaicism with a 45 , X cell lineage should be considered. In this regard, Turner females have severe growth failure and short LL in both childhood and adulthood $(21,22)$, and the height SDS of this female remained normal but below her TH SDS with a relatively short LL until her early teens and surpassed her TH SDS with a relatively long LL in her late teens. This would imply that the major growth determinant changed from the $45, \mathrm{X}$ cell lineage to the $46, X, \operatorname{dic}(X)(q 28)$ cell lineage in her middle teens. Although the underlying mechanism for the switch of the dominant growth-controlling cell lineage remains to be clarified, it appears that, in a mosaic individual with gonadal estrogen deficiency, the growth-promoting effect of SHOX overdosage can override the growthsuppressing effect of SHOX haploinsufficiency in the pubertal period of normal children when the human growth is primarily subject to gonadal estrogens. In addition, since the $45, \mathrm{X}$ cell lineage is ascribed to mitotic instability of the $\operatorname{idic}(\mathrm{X})$ chromosome, it would be less frequent in slowly dividing osteogenic cells than in rapidly dividing lymphocytes utilized for the karyotyping (23). This would also contribute to the growth promotion in her middle teens, as well as the growth preservation within the normal range in childhood. Consistent with the above notion, the previously described Japanese female with 45,X[40]/ $46, X, \operatorname{der}(\mathrm{X})[60]$ also had low-normal height until her early teens and had tall stature in her late teens (6), and relatively tall stature $(173 \mathrm{~cm},+1.8$ s.D. $)$ with eunuchoid habitus has been reported in a 23-year-old female with primary amenorrhea and 45,X/ $46, X, \operatorname{idic}(X)(q 27)$ in whom a 45,X karyotype has been detected in $80 \%$ of lymphocytes (24).

In summary, the present study suggests that the combination of SHOX overdosage and gonadal estrogen deficiency leads to a roughly constant height velocity throughout the pubertal period of normal children primarily because of the LL increase, thereby showing a sharp contrast to the worsening of growth deficiency and mesomelic appearance with puberty in females with SHOX haploinsufficiency and normal ovarian function. Further studies in patients with this combination, especially in non-mosaic patients untreated until their late teens, will permit a better assessment of clinical features of this combination.

\section{Acknowledgements}

This work was supported in part by a grant for Pediatric Research from the Ministry of Health and Welfare, by
Pharmacia Fund for Growth and Development Research, by a grant from Foundation for Growth Science, and by a grant from Human Science Foundation.

\section{References}

1 Rao E, Weiss B, Fukami M, Rump A, Niesler B, Mertz A et al. Pseudoautosomal deletions encompassing a novel homeobox gene cause growth failure in idiopathic short stature and Turner syndrome. Nature Genetics 199716 54-63.

2 Kosho T, Muroya K, Nagai T, Fujimoto M, Yokoya S, Sakamoto H et al. Skeletal features and growth patterns in 14 patients with haploinsufficiency of SHOX: implications for the development of Turner syndrome. Journal of Clinical Endocrinology and Metabolism $1999844613-4621$.

3 Clement-Jones M, Schiller S, Rao E, Blaschke RJ, Zuniga A, Zeller $\mathrm{R}$ et al. The short stature homeobox gene SHOX is involved in skeletal abnormalities in Turner syndrome. Human Molecular Genetics $20009695-702$.

4 Ogata T, Matsuo N \& Nishimura G. SHOX haploinsufficiency and overdosage: impact of gonadal function status. Journal of Medical Genetics $2001381-6$.

5 Lubin MB, Gruber HE, Rimoin D \& Lachman RS. Skeletal abnormalities in the Turner syndrome. In Turner syndrome, pp 281-300. Eds RG Rosenfeld \& MM Grumbach. New York: Marcel Dekker, 1988.

6 Ogata T, Kosho T, Wakui K, Fukushima Y, Yoshimoto M \& Miharu N. Short stature homeobox-containing gene duplication on the $\operatorname{der}(\mathrm{X})$ chromosome in a female with $45, \mathrm{X} / 46, \mathrm{X}, \operatorname{der}(\mathrm{X})$, gonadal dysgenesis, and tall stature. Journal of Clinical Endocrinology and Metabolism 200085 2927-2930.

7 MacGillivray MH, Morishima A, Conte F, Grumbach M \& Smith EP. Pediatric endocrinology update: an overview. Hormone Research 199849 (Suppl 1) 2-8.

8 Therman E, Sarto GE \& Patau K. Apparently isodicentric but functionally monocentric X chromosome in man. American Journal of Human Genetics 197426 83-92.

9 Lepping KA, Brwon CJ, Bressler SL, Gustashaw K, Pagon RA, Willard HF et al. Mapping of the distal boundary of the X-inactivation center in a rearranged $\mathrm{X}$ chromosome from a female expressing XIST. Human Molecular Genetics 19937 883-887.

10 Binder G, Eggermann T, Enders H, Ranke MB \& Dufke A. Tall stature, gonadal dysgenesis, and stigmata of Turner's syndrome caused by a structurally altered X chromosome. Journal of Pediatrics 2001138 285-287.

11 Suwa S, Tachibana K, Maesaka H, Tanaka T \& Yokoya S. Longitudinal standards for height and height velocity for Japanese children from birth to maturity. Clinical Pediatric Endocrinology $199215-14$.

12 Ogata T, Matsuo N, Tamai S, Osano M \& Tango T. Target height and target range for the Japanese [in Japanese]. Journal of the Japanese Pediatric Society $1990941635-1640$.

13 Tamai S, Matsuo N, Saito M, Sato S, Kimura K \& Osano M. Standards for sitting height, leg length, and sitting height/leg length ratio for Japanese children [in Japanese]. Journal of the Japanese Pediatric Society 199296700.

14 Tanner JM. Growth at Adolescence. Oxford: Blackwell Scientific Publications, 1962.

15 Murata M, Matsuo N, Tanaka T, Otsukii F, Ashizawa K, Tatara Y et al. In Radiographic Atlas of Skeletal Development for the Japanese [in Japanese]. Tokyo: Kanehara Press, 1993.

16 Conte FA, Grumbach MM \& Kaplan SL. A diphasic pattern of gonadotropin secretion in patients with the syndrome of gonadal dysgenesis. Journal of Clinical Endocrinology and Metabolism 1975 40 670-674.

17 Simpson JL, Christakos AC, Horwith M \& Silverman FS. Gonadal dysgenesis in individuals with apparently normal chromosomal complements: tabulation of cases and compilation of genetic data. Birth Defects Original Article Series 1971 2 21-28. 
18 Moltz L, Schwartz U, Pickartz H, Hammerstein J \& Wolf U. XY gonadal dysgenesis: aberrant testicular differentiation in the presence of $\mathrm{H}-\mathrm{Y}$ antigen. Obstetrics and Gynecology $1981 \mathbf{5 8}$ $17-25$.

19 Schibler D, Brook CGD, Kind HP, Zachmann M \& Prader A. Growth and body proportion in 54 boys and men with Klinefelter's syndrome. Helvetica Paediatrica Acta 197429 325-333.

20 Varrela J. Effects of X chromosome on size and shape of body: an anthropometric investigation in 47,XXY males. American Journal of Physical Anthropology $198464233-242$.

21 Brook CGD, Murset G, Bachman M \& Prader A. Growth in children with 45,XO Turner's syndrome. Archives of Disease in Childhood $197449789-795$.
22 Rongen-Westerlaken C, Rikken B, Vastrick P, Jeuken AH, de Lange MY, Wit JM et al. Body proportions in individuals with Turner syndrome. European Journal of Pediatrics 1993152 813-817.

23 Nazarenko SA, Timoshevsky VA \& Sukhanova NN. High frequency of tissue-specific mosaicism in Turner syndrome patients. Clinical Genetics 199956 59-65.

24 Mirzayants GG \& Baranovskaya KI. X-X translocation in a patient with gonadal dysgenesis and the problem of phenotype-karyotype correlations. Human Genetics $1978 \mathbf{4 0} 249-257$.

Received 28 December 2001

Accepted 7 May 2002 